\title{
Mulheres imigrantes alemãs no Rio Grande do Sul: uma análise das construções e discursos
}

German immigrant women in Rio Grande do Sul: analyses of construction and speeches

\section{Samanta Ritter}

Universidade do Vale do Rio dos Sinos - UNISINOS - São Leopoldo - Rio Grande do Sul - Brasil

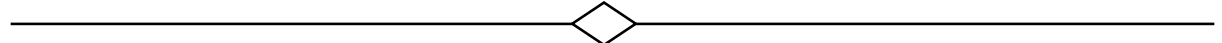

Resumo: O presente trabalho está inserido no projeto de pesquisa Imigrantes em ação: organização social e participação política. Estudo comparado sobre a imigração no Brasil, Argentina e Chile - séculos XIX e XX e está vinculado ao Núcleo de Estudos Teuto-brasileiros (NETB) da Universidade do Vale do Rio dos Sinos (UNISINOS). No campo da História da Imigração, as pesquisas que discutem sobre as mulheres precisam ser exploradas a fim de reconhecer as particularidades e contribuições das imigrantes como agentes históricas. Identificar os discursos e concepções que foram elaborados sobre as mulheres imigrantes e descendentes, tanto pela historiografia clássica quanto pela nova historiografia, é necessário para compreender o que é ser mulher imigrante ao longo do século XIX e qual sua participação na sociedade. Com a intenção de contribuir à história das mulheres, serão consultados escritos acerca das imigrantes alemãs que vieram ao Rio Grande do Sul para conhecer e analisar as construções do gênero feminino nos estudos da imigração. Comparar os discursos clássicos com os discursos revisados é significativo, pois além de verificar as mudanças de discursos e concepções, também apontam as lacunas a serem problematizadas.
\end{abstract}

Palavras-chave: Imigração alemã. Mulheres imigrantes. Discursos.

\begin{abstract}
The present study is inserted in Imigrantes em ação: organização social e participação política. Estudo comparado sobre a imigração no Brasil, Argentina e Chile - séculos XIX e XX project and it is vinculated with the Núcleo de Estudos Teutobrasileiros (NETB) of Universidade do Vale do Rio dos Sinos (UNISINOS). In the field of Immigration History, the researches that discuss about the women need to be explored in the order to recognize the particularities and contributions of the women as historical agents. Identify the speeches and conceptions that have been elaborated about the immigrant women and descendants, as far by classical historiography as by new historiography, has been required to understand what is to be an immigrant woman throughout the 19th century and what your participation in the society. With the intention of contributing with Women's History, will be consulted relevant documentation about female German immigrants that came to Rio Grande do Sul with the intent of learn and analyze the construction of the female gender in the immigration studies. Compare classical and reviewed speeches it's significant because enables verify the changes of conception and speeches, and also point the gaps going to be problematized.
\end{abstract}

Keywords: German Immigration. Immigrant women. Spechees. 


\section{Introdução}

"Aliás, a única mulher de que se tem memória no século

XIX é Jacobina Mentz Maurer..., mas que memória?"

(DREHER, 2014, p. 7)

O trecho acima transcrito indica problemáticas: qual é a mulher que o campo da Imigração conhece? Quais são as mulheres que o campo da Imigração desconhece? Tais questionamentos desencadeiam outros, que nos conduzem a refletir sobre o espaço e os silenciamentos acerca das mulheres em geral ao longo da História.

Segundo Michel de Certeau (1982), a historiografia é constituída pela escrita elaborada a partir das representações do que foi designado como passado. Certeau (1982) acrescenta que a historiografia, quando aliada a estruturas de poder, obtém força e legitimidade para seu discurso. A relação entre homens e mulheres é um exemplo de relação de poder, na qual os discursos produzidos favorecem aos homens.

Se atentarmos para a escrita da História, desenvolvida a partir dos espaços públicos que não eram frequentados pelas mulheres, como afirma Michelle Perrot (2007), e elaborada por vozes masculinas que elegeram 0 homem como representante do "nós" universal, verificaremos que os discursos silenciaram as mulheres: "ao descreverem as mulheres, sendo seus porta-vozes, (...) ocultaram-nas como sujeito, tornaram-nas invisíveis". (COLLING, 2014, p.21).

Sobre as fraturas do presente $^{1}$, como a subordinação feminina e sua invisibilidade na História, Michel Foucault (1996) afirma que é necessário compreender como foram construídos os discursos para poder desconstruí-los. As relações entre homens e mulheres foram baseadas em discursos hierarquizados e "ao se admitir o caráter de construção que a história possui, inclusive o papel de homens e mulheres na sociedade, é possível criar o que Michel Foucault chamou de 'fraturas do presente'

1 Por exemplo, na relação entre homens e mulheres, os discursos produzidos que privaram as mulheres de suas próprias escolhas ainda estão presentes na sociedade atual. pois, se algo não foi sempre assim, nada determina que assim se conserve" (COLLING, 2014, p.22).

O campo da história das mulheres, aliado a análise proporcionada pela categoria de gênero, colabora para romper com o silêncio imposto ao feminino. Como afirma Joan Scott, apropriar-se do conceito de gênero é compreender "que qualquer informação sobre as mulheres é necessariamente informação sobre os homens, que um implica o estudo do outro" (1995, p.75). O conceito, segundo Scott (1995), rejeita as explicações biológicas baseadas nos sexos e preocupa-se com as construções culturais. As construções culturais são fortemente marcadas e influenciadas pelo poder hierarquizado entre os sexos, pois "as mulheres, assim como os homens, são simplesmente um efeito de práticas discursivas e não discursivas" (COLLING, 2014, p. 33-34).

Retornando às indagações iniciais, compreendemos melhor o que Michelle Perrot expressa ao escrever que "é preciso ser piedosa ou escandalosa para existir" (2007, p. 18). A resposta da primeira pergunta, a imigrante que conhecemos, Jacobina Mentz Maurer, "ficou na história" como referência de mau exemplo, de "escandalosa". O livro do Padre Ambrósio Schupp descreveu a colona de forma depreciativa. A imagem negativa divulgada pelo livro foi relativizada em pesquisas realizadas por Janaína Amado e Daniel Luciano Gevehr, entre outros.

A resposta para a segunda interrogação contempla a pluralidade de mulheres alemãs ainda por se conhecer. Alguns pesquisadores como Daniel Luciano Gevehr e Marlise Regina Meyrer já consideraram a mulher como agente histórico em suas pesquisas: o primeiro, possibilitando um novo olhar para o episódio Mucker ${ }^{2}$ e sua líder, Jacobina Maurer; a segunda, apresentando mulheres pertencentes à burguesia teuta que se desenvolveu no Rio Grande do Sul e sua formação em uma

\footnotetext{
2 Episódio no qual forma-se um grupo religioso, liderado por Jacobina Mentz Maurer, no morro Ferrabraz, atual município de Sapiranga. O grupo chamado de Mucker (falsos beatos) despertou a oposição entre colonos e as autoridades da região. O Império interferiu, e através do conflito armado, em 1874, a maior parte dos Mucker foi morta, inclusive a líder Jacobina Maurer.
} 
instituição de ensino do município de Novo Hamburgo.

Como inquietação ao que se refere às mulheres ainda desconhecidas, notamos a necessidade de estudos com essa temática no campo da História da Imigração. Nesse sentido, nos propomos a analisar aspectos do livro $A$ colonização alemã e o Rio Grande do Sul, de Jean Roche, e do artigo Da roça para cidade: representações de gênero sobre as mulheres teuto-sul-rio-grandenses na passagem do século XIX para o século $X X$, de Daniel Luciano Gevehr e Marlise Regina Meyrer, para colocar à luz as particularidades e contribuições das mulheres alemãs no processo da Imigração.

Através do livro e do artigo temos como finalidade, não uma discussão historiográfica ou a análise completa das obras, mas conhecer como a historiografia, nos trabalhos selecionados, tratou as mulheres alemãs. Em específico, objetivamos analisar e comparar os discursos e as concepções relacionadas às imigrantes e descendentes do século XIX para elucidar as suas particularidades e indicar lacunas a serem problematizadas.

\section{Historiografia e as obras selecionadas}

Sobre a historiografia da imigração, Martin Dreher (2014) aponta a estruturação de três matrizes interpretativas construídas entre 0 intervalo da Primeira e Segunda Guerra Mundial. A primeira delas, relacionada aos autores do Instituto Histórico e Geográfico do Rio Grande do Sul, é marcada pela narrativa que enaltece a ordem e o trabalho dos imigrantes. Além de estereótipos homogêneos, a ideia de isolamento das colônias também é divulgada.

A segunda matriz é desenvolvida pelos padres jesuítas alemães, que escrevem alertando sobre a importância de manutenção dos costumes católicos e da transmissão destes para as gerações mais novas. A terceira é a matriz formada por descendentes de imigrantes alemães luteranos. Desenvolvidos com influência do positivismo alemão, seus estudos abordavam temas que ainda não haviam sido discutidos, como os Brummer, por exemplo.

A colonização alemã e o Rio Grande do Sul, livro de Jean Roche, é colocado por Dreher (2014) como uma obra divisora entre as três primeiras matrizes e os trabalhos de pesquisa que surgem depois. O livro "é um trabalho rico em termos de dados históricos e sociológicos. Tem, contudo, um eixo analítico centrado na especificidade da colonização alemã e no desenvolvimento das colônias, designadas de agrícola, comercial e industrial" (DREHER, 2014, p. 20). Desse modo, sua obra constitui-se como um ponto de partida:

\begin{abstract}
"Roche é um clássico. Ele pode estar superado em alguns aspectos, mas não se pode estudar a colonização alemã no Rio Grande do Sul sem consultá-lo. Os estudos que se seguiram aos de Roche vão detalhar ou contrariar temáticas por ele levantadas. Por isso é possível dizer que em sua produção há uma retomada dos estudos históricos sobre a imigração e colonização alemã no Rio Grande do Sul" (DREHER, 2014, p. 20).
\end{abstract}

Sendo a produção de Roche de tamanha importância para a continuidade dos estudos, Dreher (2014), aponta que os trabalhos que seguiram aos de Roche vão detalhar e até mesmo contradizer questões que abordou em seu livro. "Há um antes e um riquíssimo depois de Roche” (DREHER, 2014, p.20): neste "depois", as pesquisas foram sendo aprofundadas e tornando-se cada vez mais significativas. É neste "depois" que podemos incluir o artigo Da roça para cidade: representações de gênero sobre as mulheres teuto-sul-rio-grandenses na passagem do século $X I X$ para o século $X X$. As pesquisas dessa matriz apresentam desconstruções de estereótipos e novas interpretações sobre os diversos aspectos políticos, econômicos e sociais da história da imigração e colonização.

Tendo contextualizado o tipo de produção e sua inserção na historiografia, passaremos a seguir para a discussão e análise das obras. 


\section{As construções e os discursos acerca das mulheres alemãs}

A colonização alemã e o Rio Grande do Sul é uma obra publicada em dois volumes no ano de 1969 pela Editora Globo, com autoria de Jean Roche ${ }^{3}$.

Aborda temáticas desde o relevo do estado até mapas eleitorais.

Direcionando a leitura para identificar, em específico, trechos nos quais as mulheres fossem problematizadas, verifico que pouco consta sobre elas. O livro de Jean Roche apresenta uma escrita androcêntrica: o colono, o comerciante, o artesão. Muitos nomes masculinos são apresentados ao longo da obra: quando abrem negócios como cervejarias, curtumes ou fábricas têxtis, por exemplo, ou quando o autor apresenta inventários, elucidando que as posses familiares estavam sempre vinculadas ao homem e por ele eram administradas.

Sobre as mulheres imigrantes e descendentes desenvolve pouco em sua obra, e o pouco que há escrito cria uma imagem uniforme delas. Quando mencionadas, o são pelo estereótipo de colonas trabalhadoras ou quando sua presença está inserida com menção à família. Em uma linha informa que as mulheres alemãs, ainda, foram operárias das indústrias de tecelagem. Embora seu livro destaque os homens de negócios, não inclui as mulheres nesse contexto.

O artigo, Da roça para cidade: representações de gênero sobre as mulheres teuto-sul-riograndenses na passagem do século XIX para 0

\footnotetext{
3 Jean Roche veio para o Rio Grande do Sul ano de 1945, quando sua esposa, Nancy Roche, foi transferida da França para fundar em Porto Alegre a Aliança Francesa. Atuou como professor de língua francesa na Pontifícia Universidade Católica e na Universidade Federal do Rio Grande do Sul; Dreher destaca o grande interesse de Roche "para a Literatura, para as Letras" (2014, p. 9)que podem influenciar na sua escrita. Segundo Dreher (2014), em 1953 deixou Porto Alegre, levando anotações e documentações sobre o do Rio Grande e, em específico, sobre a colonização alemã no estado. Essa documentação foi transformada em sua tese La colonisation allemande et le Rio Grande do Sul pela Universidade de Paris, Sorbonne, defendida no ano de 1962. Roche também escreveu sobre a colonização alemã no estado do Espírito Santo, entre outros assuntos que abordou. Aspectos históricos, culturais e geográficos estão presentes em suas pesquisas que resultaram em obras de referência para o estudo da imigração e colonização alemã.
}

século XX, foi escrito no ano de 2016, pelos autores ${ }^{4}$ Daniel Luciano Gevehr e Marlise Regina Meyrer. Diferentemente do livro de Roche, tem como objeto de estudo as mulheres; logo, a forma de escrita e o conteúdo são direcionados a elas. Como o próprio título do artigo indica, colonas e burguesas são analisadas; da esfera rural, Jacobina Mentz Maurer e, da esfera urbana, estudantes da Evangelisches Stift ${ }^{5}$.

A respeito do ambiente rural, os autores discutem as representações negativas acerca de Jacobina e de como ela tornou-se um "mau exemplo" para as demais colonas ao assumir um papel de destaque. Sobre o ambiente urbano, o grupo de alemães busca distinguir-se dos colonos e constrói essa diferenciação através do processo de aburguesamento; no artigo, o símbolo para tal distinção é produzido pela instituição de ensino, no qual as estudantes aprendem, sobretudo, o modelo de comportamento ideal de boa esposa e boa dona de casa.

Elegemos categorias - educação, trabalho, sociabilidade e casamento - que vão auxiliar na comparação dos discursos e concepções dos estudos acima indicados para conhecer algumas facetas das mulheres imigrantes e suas descendentes.

\section{Educação}

O quesito educação está desenvolvido no livro de Jean Roche, no qual apresenta a dificuldade de acesso ao ensino público para os colonos, pois o

\footnotetext{
${ }^{4}$ Daniel Luciano Gevehr é doutor em História pela Universidade do Vale do Rio dos Sinos. Sua tese de doutorado, intitulada Pelos caminhos de Jacobina: memórias e sentimentos res(significados) (2007), demonstra uma escrita atenta com a temática de gênero e as construções culturais a cerca do movimento Mucker. Marlise Regina Meyrer é doutora em História pela Pontifícia Universidade Católica do Rio Grande do Sul. Seu estudo para dissertação de mestrado, intitulada Evangelisches Stift: uma escola para moças das melhores famílias (1997), corrobora para o conhecimento de uma parcela de mulheres alemãs burguesas que se distinguiam das colonas, destacando as diferenças de uma etnia tida como homogênea. Ambos os autores, no artigo selecionado para esse trabalho, demonstram 0 domínio de temáticas já trabalhadas anteriormente em suas pesquisas com atenção ao protagonismo feminino, indicando no artigo, aproximações e distanciamentos entre as alemãs colonas e as alemãs burguesas.

5 Instituição de ensino para "as moças das melhores famílias" como se referem os autores à instituição ao longo do artigo. Atualmente é a Fundação Evangélica, escola do município de Novo Hamburgo/RS.
} 
português era a língua utilizada nas escolas. O autor escreve que, aos poucos, o ensino particular, em língua alemã, foi surgindo para atender aos alemães que tinham condições de efetuar pagamento pelas aulas, e que também os colonos passaram a exigir professores com conhecimento em língua alemã para ensinar nas escolas públicas da colônia. Roche acrescenta que a "a escola teuto-brasileira desempenhou um grande papel: sem dúvida permitiu aos teuto-rio-grandenses conservar o uso da língua alemã até à quarta ou quinta geração" (ROCHE, 1969, p. 670).

O artigo, evidentemente, explora o tema da educação por tomar como objeto alunas da Evangelisches Stift. Além de apontar como ocorria o ensino na instituição, o artigo também indica, em um pequeno trecho, a instrução entre os colonos, complementando as informações de Roche, e a instrução entre os burgueses. O excerto abaixo elucida tais condições:

“(...) as escolas comunitárias, destinadas exclusivamente ao ensino elementar e dirigidas, principalmente à população rural, isto é, aos colonos e às mais avançadas educandários de aperfeiçoamento - nos quais os teuto-brasileiros recebiam uma educação diferenciada. Estas últimas situavam-se geralmente nos núcleos urbanos e destinavam-se apenas a uma fração do grupo, que poderia prolongar a educação dos filhos e arcar com os custos elevados deste ensino" (GEVEHR; MEYRER, 2016, p. 70).

Entre os colonos, a permanência na escola era menor. Roche não apresenta maiores informações sobre o estudo e nem sobre quem frequentava a escola (se meninos e meninas ou mais meninos do que meninas e assim por diante). Por sua vez, os autores Gevehr e Meyrer escrevem sobre a experiência escolar da colona Jacobina Maurer. Embora frequentasse a escola quando criança, não aprendera a ler. Quando aprendeu a ler em alemão já era adulta e foi ensinada pelo professor Hardes Fleck. Jacobina passara a ler e interpretar a Bíblia para os colonos que frequentavam sua casa. Com isso, porém, a colona subvertia a ordem, pois "o saber é contrário a feminilidade. Como é sagrado, o saber é o apanágio de Deus e do Homem, seu representante sobre a terra. (...) As religiões do Livro (judaísmo, cristianismo, islamismo) confiam a Escritura e sua interpretação do homem" (PERROT, 2007, p. 91). A incursão ao mundo masculino, no qual apenas homens (padres e pastores) tinham a permissão para evangelizar os fiéis, faz a má fama de Jacobina Maurer como profetiza sedutora e fanática religiosa, corruptora dos colonos.

Em contraste com o mundo rural, a Evangelisches Stift, assim como os demais educandários de aperfeiçoamento urbanos, tinha seu público e propósito definidos: "Essas escolas (...), tinham como alvo as filhas das famílias abastadas, sendo sua educação parte do processo de aburguesamento pelo qual passava a sociedade de então (...)" (GEVEHR; MEYRER, 2016, p. 71). O currículo da instituição incluía

“(..) as disciplinas de Trabalhos Manuais, Música, Línguas e Conhecimentos Gerais, todas com ampla carga horária (...). Trabalhos Manuais era a disciplina de maior carga horária do currículo (...) com 12 a 17 horas semanais quando se ensinavam '(...) todas as sortes de trabalhos singelos e artificiais feitos à agulha, tais são: crochet, frivolité, crivo, renda irlandesa, costuras, bordados a ouro, a seda em branco, em étamine, em filó e pontos de malha'. As aulas incluíam conteúdos como a organização da casa, cozinha, pintura em tela e jardinagem" (GEVEHR; MEYRER, 2016, p. 73-74).

O currículo das estudantes era direcionado para a formação de boas donas de casa e boas esposas, relegando ao segundo plano a educação formal. Segundo Michelle Perrot e Geneviève Fraisse (1991), as mulheres faziam parte de um código social coletivo - elaborado pelos homens - que uniformizava e ditava seus comportamentos. Logo, a instituição Evangelisches Stift não é um caso isolado: seguia as recomendações de inúmeros teóricos da época, que indicavam quais os saberes eram necessários para a mulher.

"É preciso, pois, educar as meninas, e não exatamente instruí-las. Ou instruí-las apenas no que é necessário para torná-las agradáveis e úteis: um saber social, em suma. Formá-las para seus papéis futuros de mulher, de dona de casa, de esposa e mãe. Inculcar-lhes bons hábitos de economia e de higiene, os valores 
morais de pudor, obediência, polidez, renúncia, sacrifício... que tecem a coroa das virtudes femininas" (PERROT, 2007, p. 93).

$\mathrm{Na}$ instituição Evangelisches Stift, as mulheres eram preparadas para permanecer em ambiente privado, no qual a educação formal não era necessidade. Valores morais e educação, sim. Esses valores ensinados na instituição eram aprovados pela sociedade da época e se chocam com o caso de Jacobina Maurer, que recebeu uma educação informal e que, por meio do conhecimento das letras, obteve um espaço de protagonismo, não aprovado pela sociedade.

\section{Trabalho}

Jean Roche, afirma mais de uma vez em seu livro, que o trabalho na colônia necessitava da colaboração de toda família: “(...) a simples sobrevivência biológica só foi possível graças ao trabalho de tôda família (...)" (ROCHE, 1969, p. 480). Neste trecho, notamos que a mulher está incluída na palavra família. Porém, especificamente sobre o trabalho da mulher dentro do grupo familiar, pouco foi escrito. Roche descreve detalhadamente o trabalho, negócio e ofícios, os quais os homens poderiam ocupar; e, quando escreve sobre o trabalho da mulher colona, o faz permeado pelo trabalho que o homem realiza em conjunto:

"É tôda a família que trabalha, sobretudo, na primeira geração. (...) os homens, as mulheres, e muitas vezes as crianças, são absorvidos, da manhã à noite, no desbravamento da floresta. Se a derrubada e a queimada são tarefas masculinas, as mulheres semeiam, plantam, mondam, colhem, ordenham e devem, ainda, fazer o pão, a manteiga, a lixívia, etc. (...). Também a avó, que fica em casa, cuida da cozinha (...)" (ROCHE, 1969, p. 559).

O excerto acima evidencia a concepção estereotipada da mulher colona e trabalhadora. O trabalho "mais delicado" - se comparado à derrubada da mata - de semeação, colheita e ordenha é realizado pela mulher. Apesar das funções exercidas ocorrerem fora do espaço físico da casa, os afazeres da imigrante são voltado para o espaço privado.
Chamo atenção para o verbo devem, utilizado pelo autor. Para além da descrição do trabalho feminino, a escolha de Roche pelo verbo dever atribuiu obrigatoriedade única para realização do trabalho doméstico pelo sexo feminino. O trabalho doméstico era um trabalho feminino por excelência, no qual a mulher buscava seu espaço de atuação e protagonismo:

\begin{abstract}
"Se a casa era o 'templo', seu altar era a cozinha. O fogão, o sacrário. Este universo feminino, povoado de mães, irmãs e filhas, tinha também seu altar, sua mesa de alquimista, seu confessionário, seu tribunal, sua caixa de pandora - onde e de onde emanava o poder doméstico, concretizado no fogão. Era em torno dele que a mulher exercia o domínio da casa: enquanto preparava os alimentos para a família (o poder da sobrevida), ouvia as queixas, dirimia contendas, ensinava catecismo aos filhos menores, transmitia códigos de valores, cobrava comportamentos, controlando a todos, especialmente as filhas e noras (e através delas, filhos e netos)" (FAVERO, 2002, p.124).
\end{abstract}

Apesar de sua importância, o trabalho doméstico foi e ainda é invisível e desvalorizado pela sociedade. Percebemos que "o trabalho doméstico resiste às evoluções igualitárias. Praticamente nesse trabalho, as tarefas não são compartilhadas entre homens e mulheres" (PERROT, 2007, p. 115) e que a construção cultural - de que o doméstico é de exclusiva responsabilidade feminina - ainda persiste na sociedade atual.

Gevehr e Meyrer, por sua vez, evidenciam outra face da mulher alemã, que vai contra ao estereótipo de laboriosa. As estudantes burguesas, ao invés de serem ensinadas a executar as funções domésticas, eram ensinadas a coordená-las:

\footnotetext{
"Os critérios de distinção tornavam-se mais importantes na medida em que o outro, do qual se pretendia diferenciar, partilhava de alguns aspectos em comum, como a etnicidade e neste caso o gênero. (...) a diferença entre a alemã que realizava trabalhos domésticos para o seu sustento e aquela que aprendia técnicas domésticas na escola, para administrar a casa, ou seja, dirigir os trabalhos domésticos" (GEVEHR; MEYRER, 2016, p. 69,70).
} 
Sem a necessidade de executarem as funções domésticas, o tempo livre devia ser preenchido. $O$ ócio era condenado pelos burgueses, portanto "uma boa dona de casa deveria manter-se sempre ocupada" (GEVEHR; MEYRER, 2016, p. 74). A ideia de trabalho recai para o artesanato. As técnicas de bordado, pintura e jardinagem, aprendidas na escola, auxiliariam as mulheres a manter seu cotidiano ativo.

Sobre as mulheres que viviam no espaço urbano, mas sem contar com os recursos financeiros da classe burguesa apresentada pelo artigo de Gevehr e Meyrer, são superficialmente mencionadas por Roche: “(...) numa das seções de tecelagem, das usinas Renner, encontramos 190 operários e operárias" (ROCHE, 1969, p. 588).

Podemos observar que a absorção de mulheres alemãs na indústria do Rio Grande do Sul esteve relacionada ao tipo de função aceita para a mulher pelo mundo Ocidental: para garantir circulação no espaço público do mundo do trabalho, era indicado buscar as atividades relacionadas e direcionadas ao sexo feminino. "O têxtil foi o grande setor de emprego das mulheres, nas fábricas e nos ateliês" (PERROT, 2007 , p. 119). Devido aos seus "dons naturais", as mulheres, "que nasceram "com uma agulha entre os dedos"' (PERROT, 2007, p. 122), ingressaram, em maior número, na indústria dos tecidos.

\section{Sociabilidade}

Os alemães são reconhecidos pelas suas festas, sendo a mais conhecida o Kerb. Em ambiente rural ou urbano,

\begin{abstract}
“(..) a sociabilidade desenvolvida nas cidades rio-grandenses ocorreu primeiramente no espaço privado das casas onde se recebia a elite local para saraus, ou sessões de canto, ou nos clubes, tanto da capital quanto do interior. O baile era a atividade social por excelência, assim como ir ao teatro e à missa aos domingos" (RAMOS, 2000, p. 49).
\end{abstract}

As festas ocorriam, primeiramente nas casas, como evidencia o excerto acima, mas, pouco a pouco, nas cidades alcançadas pelo progresso, estas passaram a ser realizadas cada vez mais nos clubes.
Tais espaços requerem comportamentos civilizados, como aponta Eloisa Helena Capovilla da Luz Ramos (2000). Em meio rural, como no livro de Roche, ou em meio urbano, como no artigo de Gevehr e Meyrer, encontramos menções sobre esses momentos e a participação feminina.

O aspecto de sociabilidade, na obra de Roche, é uma afirmação dos momentos de dança e festa entre os alemães. Em um trecho faz uma comparação entre a participação social das mulheres de etnia lusa e alemã.
"Em todas as festas, que permitem aos colonos reunir-se e esquecer o trabalho cotidiano, a dança ocupa um lugar preponderante, diferentemente das zonas rurais luso-brasileiras, onde a vida social se reserva tradicionalmente aos homens. A aparente liberdade concedida, na colônia, à mulher e à moça parecia censurável" (ROCHE, 1969, p. 642-643).

Qualificar como censurável a participação das mulheres na vida pública da colônia é destacar o comportamento das alemãs em relação às outras mulheres; as alemãs estavam fora do padrão considerado correto, deixando o ambiente privado para, em momentos de festas, frequentar o espaço público.

O artigo de Gevehr e Meyrer afirma que os momentos de sociabilidade urbana aconteciam principalmente nos clubes, nos quais as regras comportamentais exigidas às mulheres eram rígidas.

"O desenvolvimento econômico da zona colonial alemã trouxe um incremento da vida social e cultural praticada principalmente nos clubes, onde os sócios se reuniam para dançar, assistir uma peça de teatro, praticar esportes. A frequência a esses lugares requeria um tipo de comportamento adequado, principalmente das mulheres" (GEVEHR; MEYRER, 2016, p. 75).

O comportamento adequado para as jovens era crucial. Fora do ambiente privado, nos momentos em que participavam da vida pública, eram constantemente vigiadas pelas figuras masculinas, que Ihes exigiam comportamento condizente com o de uma mulher: sorrisos, mas não conversas sobre política, por exemplo. 


\section{Casamento}

O casamento, no livro de Jean Roche, aparece através da discussão de endogamia e exogamia. $\mathrm{O}$ autor aponta que a exogamia acontecia, na maioria dos casos, por parte das mulheres alemãs. Um dos motivos que possibilitou o casamento entre as etnias era a formação dos centros urbanos, onde homens e mulheres dividiam o espaço de trabalho nas indústrias que surgiam. Através de uma pergunta, questiona sobre os interesses relacionados a esse comportamento: "Não é o desejo de fugir à condição de agricultor que faz essas jovens procurarem espôso fora de sua etnia?" (ROCHE, 1969, p. 610).

Novamente quero chamar atenção para o verbo empregado - fugir. A utilização do verbo levanta hipóteses sobre suas motivações de forma áspera, como se o único motivo de casamento fosse pelo abandono da vida rural.

No artigo de Gevehr e Meyrer, o casamento da colona Jacobina Maurer, é descrito como um casamento no qual o marido não se impõe, que ao invés de coibir o comportamento fanático e enganoso da mulher, se aproveita para tirar vantagens, pois segundo os rumores da época, discutidos no artigo de Gevehr e Meyrer, João Maurer não gostava de trabalhar. Independente das intencionalidades dele, a exigência é clara: ele deve controlar sua esposa, evidenciando o significado de posse do homem sobre a mulher através do casamento.

Os autores do referido artigo também abordam o casamento como objetivo da vida das mulheres burguesas; um marco de realização e sucesso em suas vidas. Na procura por um marido "um mínimo de conhecimentos tornava-se necessários para desenvolver uma conversa, e, talvez, impressionar um futuro pretendente" (GEVEHR; MEYRER, 2016, p. 75). A Evangeliches Stift, como já mencionado, contava com as aulas de conhecimentos gerais e línguas, mas o foco do currículo era voltado para a formação de boas donas de casa e esposas; nas aulas de técnicas manuais alcançariam os atributos desejáveis para manter o matrimônio.
Cleci Eulalia Favaro (2002) escreve que o casamento cristão e a maternidade eram a única forma de regeneração do gênero feminino, sendo os principais, e muitas vezes únicos objetivos de vida das mulheres. O casamento, para Fraisse, “(...) aparece como sujeição de um sexo pelo outro, como a proclamação de um conflito entre dois sexos (...)" (1991, p. 86). Independente das motivações apontadas pelos autores Roche, Gevehr e Meyrer, para dar continuidade ao modo de vida ou por buscar uma vida melhor - o casamento era uma realidade para as imigrantes alemãs e suas descendentes; através do casamento como dependência do homem, as possibilidades eram apresentadas às mulheres.

\section{Considerações finais}

A análise das duas obras proporcionou o reconhecimento de inúmeras formas de ser mulher e dos diferentes espaços de circulação aos quais as imigrantes alemãs e descendentes tinham acesso. Colonas, burguesas ou operárias, do espaço rural ao urbano, inseridas em diferentes ambientes, que de acordo com suas possibilidades, frequentavam por mais ou menos tempo a escola, participavam das festas realizadas nas casas ou nos clubes, executavam 0 trabalho doméstico ou apenas coordenavam as tarefas.

Mesmo que sem a intencionalidade de acusações e julgamentos, Jean Roche utiliza verbos e adjetivos para o comportamento feminino, aos quais chamei atenção anteriormente, como devem, censurável, fugir, demonstrando que as construções culturais dos discursos são assimilados e perduram na sociedade. O estudo de gênero evidencia a historicidade que está em torno dos símbolos ligados aos homens e mulheres e corrobora a ideia de que

\footnotetext{
"ser homem/ser mulher é uma construção simbólica que faz parte do regime de emergência dos discursos que configuram sujeitos. Nesse sentido, é necessário criticar, desmontar estereótipos universais e valores tidos como inerentes à natureza feminina" (COLLING, 2014, p. 28).
} 
Os discursos formulados ao longo da História intencionavam manter a mulher presa a sua função biológica da reprodução e restrita ao ambiente privado, por ser frágil e incapaz de pensar e agir por si mesma. O trabalho doméstico, a dedicação ao lar, ao marido e aos filhos eram "limites da feminilidade, determinados pelos homens, (...) uma maneira clara de demarcar a sua identidade. Como se a mistura de papeis sociais lhes retirasse o solo seguro" (COLLING, 2014, p.24).

A obra A colonização alemã e o Rio Grande do Sul, clássico, escrito por Jean Roche, dedicou poucas linhas ao gênero feminino, e quando o fez, foi a partir de uma homogeneização construída de que as alemãs eram colonas trabalhadoras. Cita as operárias, fazendo referência a sua existência, mas sem realmente problematizá-las. O artigo $D a$ roça para cidade: representações de gênero sobre as mulheres teuto-sul-rio-grandenses na passagem do século XIX para o século $X X$ apresentou uma divisão no grupo mantido como homogêneo até então: as mulheres urbanas e burguesas, que distinguiam-se pela sua posição social e circulavam por espaços diferenciados em relação às mulheres colonas e operárias.

Apesar da variedade encontrada entre as mulheres alemãs, podemos identificar uma semelhança quando vemos sua figura em relação à figura masculina: evidencia-se que as mulheres, na maior parte do tempo, têm privação de sua liberdade e são dependentes da figura masculina. Por exemplo, nos momentos de sociabilidade, em clubes ou em festas realizadas em casa, eram vigiadas e cobravam-lhes comportamento exemplar; na necessidade de arranjar casamento; no direcionamento que a escola dava para educar suas alunas; na realização exclusiva dos trabalhos domésticos devido aos seus dons "naturais". Essas imigrantes não fogem à regra do discurso ocidental; estão no padrão de comportamento esperado, assim como as outras mulheres do século XIX.

Enquanto que a obra clássica analisada apresenta o estereótipo das trabalhadoras alemãs, o artigo amplia a percepção sobre o grupo das alemãs a partir das burguesas e desconstrói as representações tidas como verdade acerca de Jacobina, oferecendo novos olhares para a líder do episódio Mucker. As particularidades de cada uma delas elucida o esforço em seguir investigando-as para formar um panorama mais completo da imigração e colonização alemã no Rio Grande do Sul e para que se possa responder o segundo questionamento inicial de forma ainda mais justa e satisfatória.

\section{Referências}

CERTEAU, Michel de. A escrita da História. Rio de Janeiro: Forense Universitária, 1982.

COLLING, Ana Maria. Tempos diferentes, discursos iguais: a construção do corpo feminino na História, MS: Ed. UFGD, 2014.

DREHER, Martin Norberto. 190 anos de imigração alemã no Rio Grande do Sul: esquecimentos e lembranças. 2. Ed. São Leopoldo: OIKOS, 2014.

FAVARO, Cleci Eulalia. Imagens femininas: contradições, ambivalências, violências. Porto Alegre: EDIPUCRS, 2002.

FOUCAULT, Michel. A ordem do discurso Aula inaugural no Collège de France, pronunciada em 2 de dezembro de 1970. São Paulo: Edições Loyola, 1996.

FRAISSE, Geneviève; PERROT, Michelle. História das Mulheres no Ocidente - Volume 4: O século XIX. Porto: Edições Afrontamento, 1991.

GEVEHR, Daniel Luciano; MEYRER, Marlise Regina. Da roça para a cidade: representações de gênero sobre as mulheres teuto-sul-riograndenses na passagem do século XIX para o século XX. Dimensões, v. 36, p. 55-81, 2016.

PERROT, Michelle. Minha história das Mulheres. São Paulo: Contexto, 2007.

RAMOS, Eloisa Helena Capovilla da Luz. O teatro da sociabilidade: os clubes sociais como espaço de representação das elites urbanas alemãs e teuto-brasileiras - São Leopoldo 1858-1930. Tese (Doutorado), Universidade Federal do Rio Grande do Sul - UFRGS, Porto Alegre, RS, 2000.

ROCHE, Jean. A colonização alemã e o Rio Grande do Sul. Porto Alegre: Editora Globo, 1969. 
SCOTT, Joan Wallach. Gênero: uma categoria útil de análise histórica. Educação e Realidade, vol. 16, no 2, Porto Alegre, jul./dez., p. 77-91, 1995.

Ágora [ISSN 1982-6737]. Santa Cruz do Sul, v. 20, n. 01, p. 102-111, jan./jun. 2018.

http://online.unisc.br/seer/index.php/agora/index 